DOI: 10.36910/6775-2524-0560-2020-39-03

УДК: $514.181 .6+514.182$

Журило Алла Григорівна, к.т.н., доцент, https://orcid.org/0000-0003-4084-4622

Сівак Слизавета Михайлівна, к.т.н., доцент.

https://orcid.org/0000-0002-5526-8544

Національний технічний університет «Харківський політехнічний інститут»

\title{
ПОБУДОВА ПЕРСПЕКТИВИ КОЛА, ЩО НАЛЕЖИТЬ ПРЕДМЕТНІЙ ПЛОЩИНІ
}

\begin{abstract}
Журило А.Г., Сівак Є.М. Побудова перспективи кола, що належить предметній площині. У статті розглянуто основні положення щодо побудови перспективних зображень кіл, які належать предметній площині. Пояснюються складності таких побудов, пропонуються методи спрощення побудов, визначаються необхідні умови для таких побудов. Показано практичне застосування перспективних зображень, встановлена неможливість зображення кіл малих діаметрів в перспективних зображення. Тим самим, пояснюються причини можливої заміни еліпсів при виконанні перспективних зображень овалами без втрати наочності. Наведено приклади перспективних зображень кіл при виконанні креслеників.
\end{abstract}

Ключові слова: перспективні зображення, коло, еліпс, овал, практичне застосування.

Журило А. Г., Сивак Е. М. Построение перспективы окружности, принадлежащей предметной плоскости. В статье рассмотрены основные положения по построению перспективных изображений окружностей, принадлежащих предметной плоскости. Объясняются сложности такого построения, предлагаются пути упрощения построений, определяются необходимые условия для таких построений. Показано практическое применение перспективных изображений, установлена невозможность изображения окружностей малых диаметров в перспективных изображения. Тем самым, объясняются причины возможной замены эллипсов при выполнении перспективных изображений овалами без потери наглядности. Приведены примеры перспективных изображений окружностей при выполнении чертежей.

Ключевые слова: перспективные изображения, окружность, эллипс, овал, практическое применение.

Zhurilo A. G., Sivak E. M. Building the perspective of a circle that belongs to the subject plane. The article discusses the main provisions for the construction of perspective images of circles belonging to the subject plane. The complexity of such a construction is explained, ways to simplify the construction are suggested, and the necessary conditions for such constructions are determined. The practical application of perspective images is shown. it is established that it is impossible to image circles of small diameters in perspective images. This explains why ellipses can be replaced with ovals when performing perspective images without losing visibility. Examples of perspective images of circles when performing drawings are given.

Key words: perspective images, circle, ellipse, oval, practical use.

Постановка проблеми. Незважаючи на широкий розвиток комп'ютерної техніки та широке застосування iï для виконання креслеників, появі вже декількох поколінь програм КОМПАС, AUTOCAD та їхніх аналогів, перспективні проекції широко використовуються у машинобудуванні та архітектурі. Для їх опанування потрібно добре знати їхні властивості та правила їхньої побудови, раціонального розташування, 3 метою отримання найбільш вигідного зображення, та зменшення кількості різних побудов, тощо. На жаль, перспективні проекції мають відповідні лише їм специфічні властивості, які ускладнюють побудову креслеників та їхніх частин, та, відповідно, використання вказаних проекцій на практиці.

Аналіз останніх досліджень і публікацій. Питання щодо точних графічних побудов має велику історичну давнину, беручи свій початок ще в роботах Архімеда, Евкліда та інших вчених. 3 вичерпною повнотою і строгою науковою обгрунтованістю теорія точних метричних побудов була розроблена математиком Гаспаром Монжем, який у 1795 - 1799 рр. опублікував результати своєї двадцятирічної роботи під назвою «Нарисна геометрія» [1].

Серед імен, з якими пов'язаний розвиток наукової праці в області перспективних проекцій, можна згадати видатних вітчизняних вчених: Н. М. Бескіна, О. О. Вольберга, Н. О. Глаголєва, Є. А. Глазунова, А. І. Добрякова, Д. І. Каргина, I. І. Котова, М. О. Риніна, С. О. Смирнова, М. Ф. Четверухіна, С. О. Соловйова [2-6].

У даний час теорія перспективи розроблена докладно і висвітлена в численних працях 3 нарисної геометрії. Питання ж практики побудови перспективних зображень висвітлені в літературі недостатньо. У практиці побудови перспективних зображень часто виникають значні труднощі, обумовлені не тільки недостатньою підготовкою виконавця, але і складністю окремих задач, що вимагають спеціального роз'яснення [6-8].

Положення ускладнюється ще й тому, що за останні $20 . .30$ років практично не публікувалося дослідних робіт із практики побудови перспективних зображень та ii основних законів. Ті ж роботи, що були опубліковані раніше, у більшості випадків розглядають найбільш відомі методи 
перспективних зображень, та розглядають найбільш нескладні задачі.

Невирішені частини проблеми. Метою статті $\epsilon$ визначення причин широкого розповсюдження перспективних зображень, обгрунтування основних властивостей при побудові тіл обертання.

\section{Мета дослідження.}

Перспективні зображення $\epsilon$ найважливішим розділом побудови об'ємних зображень. Перспектива підпорядковується законам і правилам, за якими можна зображати предмети так, як вони представляються нашому оку в просторі. Відомі побудови перспективних зображень методом архітекторів, перспективної сітки, лінійна, панорамна перспектива та інші ії види. Спосіб архітекторів можна вважати різновидом способу сліду променя, коли перспективу не поєднують 3 фронтальною проекцією, а переносять на вільне поле кресленика, або на інший аркуш, при цьому масштабуючи зображення. Як випливає з назви, спосіб широко застосовується для зображення призм, кубів, паралелепіпедів, як складових будівель і споруд. На практиці широко застосовують методи архітекторів з однією точкою сходу, з двома, з опущеним (піднятим) планом і з бічною стіною. При побудові окремої будівлі площину картини зазвичай проводять під кутом $30 \ldots 35^{\circ}$ до фасаду. Для полегшення побудови бажано провести картину через будь-який кут споруди.

Головний промінь повинен бути, перпендикулярним картині і бути бісектрисою кута зору або мати положення близьке до бісектрисі. Кут зору приймається в межах $30 \ldots 35^{\circ}$, але не більше $40^{\circ}$. Для об'єктів, що мають розвиток в горизонтальній площині, точка зору обирається по куту в плані, а для об'єктів, що мають розвиток у вертикальній площині - по куту у вертикальній площині. У будьякому випадку головна точка картини повинна знаходитися в середній третині зображення перспективи. Від цього буде залежати наочність зображення, що наведено на Рис. 1.

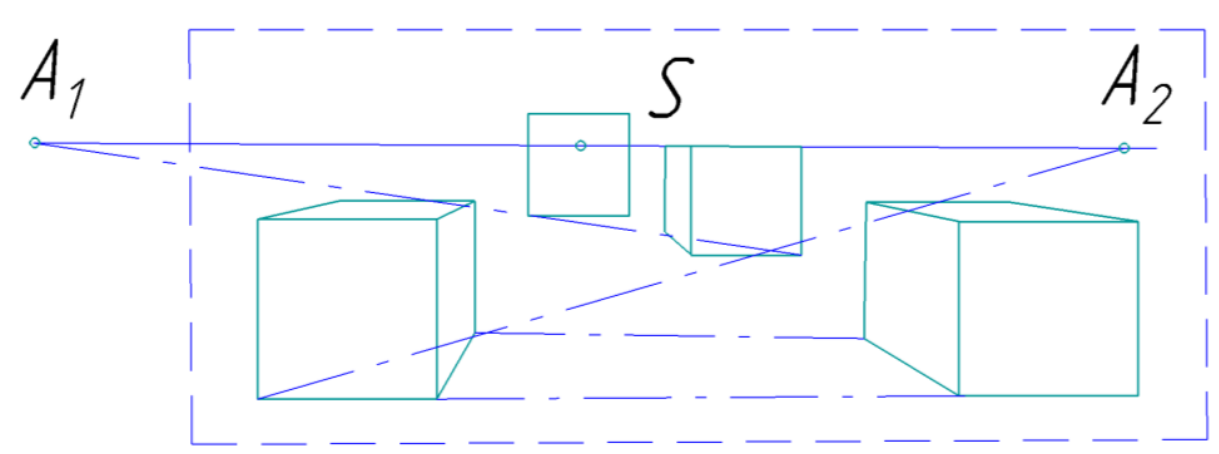

Рис. 1. Наочність зображення кубів на перспективному зображенні в залежності від положення щодо горизонту і точки зору.

При побудові перспективних креслеників досить часто доводиться викреслювати перспективу кола не тільки як перспективу існуючої кривої на даному предметі, але і як допоміжну криву для вирішення деяких геометричних завдань.

Перспективою на площині для кола є еліпс, який зображується допоміжними побудовами ряду точок, які йому належать. Ці точки можливо визначити декількома способами:

- 3 побудови перспектив ряду точок, обраних на даній окружності;

- 3 побудови еліпса за двома сполученими діаметрами, з подальшим визначенням декількох точок, що йому належать;

- за визначенням ряду точок зазначеного еліпса.

Що ж стосується ряду точок, які належать еліпсу, то вони повинні бути визначені на такій відстані одна від одної, щоб з'єднуючи кожну суміжну пару таких точок дуги еліпса могли б бути прийняті без значної похибки, за прямолінійні відрізки або ж за дуги кіл яких би то не було радіусів. Так як дуги еліпса в різних частинах кожної його чверті не мають однакової кривизни, то, отже, і відстані між рядом точок, що визначають обрис будь-якої чверті еліпса, будуть не однакові: при вершині, яка визначається великою віссю, вони повинні бути обрані ближче одна до іншої, а в міру наближення до вершини, яка визначається малою віссю, відстані між ними можна послідовно збільшувати. Крім того відстані між рядом точок, що визначають досить точно накреслення чверті еліпса, змінюються в залежності відносини між його півосями. Так як одна і та ж окружність (3 незмінним радіусом) може перетворюватися в перспективі в еліпси з різними відносинами між півосями, в залежності від того, наскільки вона буде віддалена як від полюса, так і від центральної площини. Зазначене положення виключає виділення єдиного правила поділу даної окружності на такі дуги, який дозволяли б побудови в перспективі необхідної величини дуги еліпса перспективи () Журило А. Г., Сівак Є. М. 
даної окружності. Тому, найбільш раціональний спосіб побудови перспективи кола (еліпса) буде той, який дає можливість визначати на картинній площині точку, що належить еліпсу (перспективі даної окружності) в заданому місці.

Найбільш поширеним способом побудови кола в перспективі є спосіб описаного квадрата. Цей спосіб передбачає, що спочатку будується перспектива квадрата, в який потім вписується еліпс. Як приклад, можна розглянути процес побудови перспективи горизонтально розташованої окружності, яка вписана в квадрат зі сторонами паралельними картинної площині (Рис. 2).

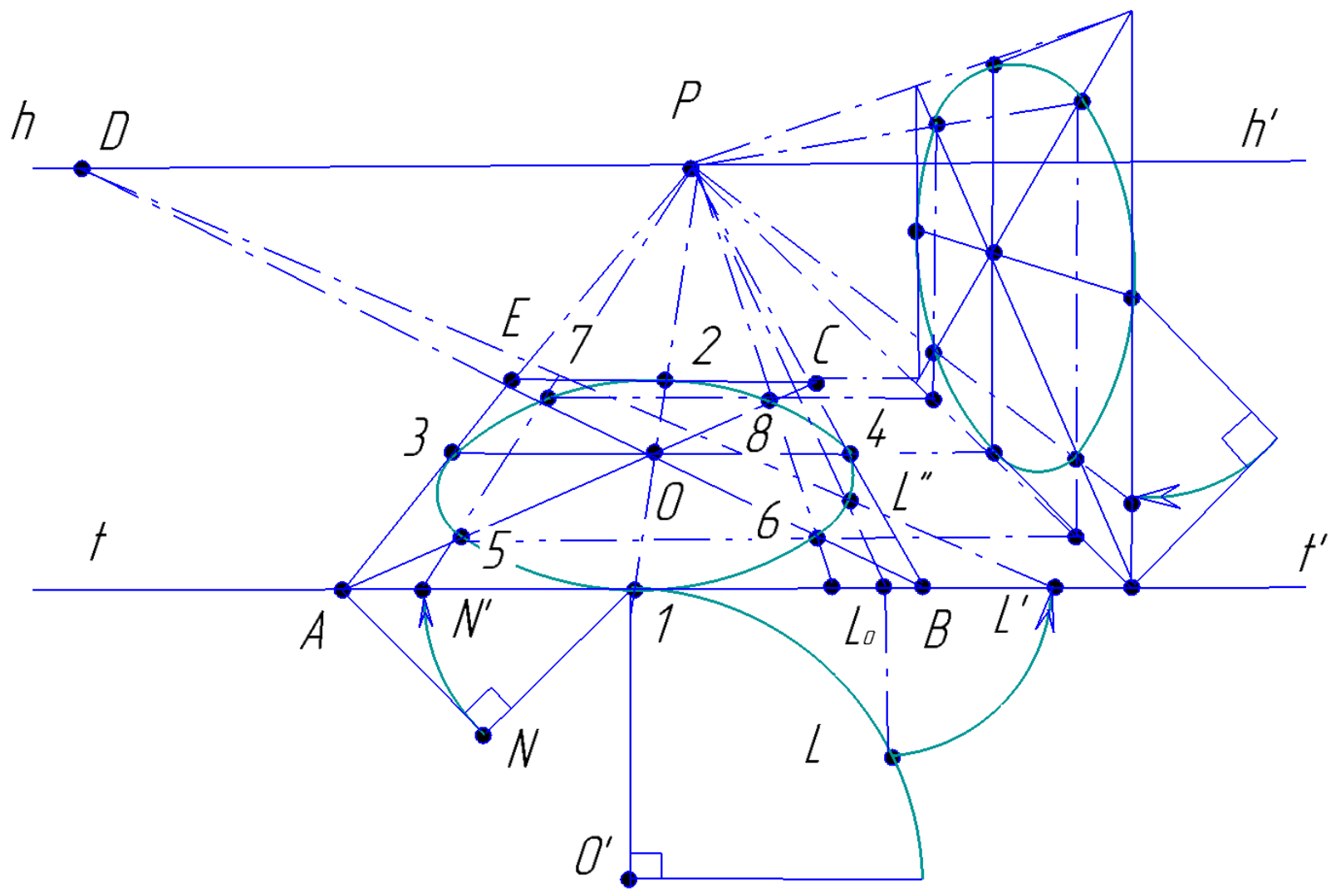

Рис. 2 - Побудова кола способом описаного квадрата у фронтальній перспективі

Побудова квадрата ведеться наступним чином. Намічається найближча до глядача сторона квадрата $\mathrm{AB}, з$ вершин якої проводяться прямі в головну точку $P$. Сторони $A B$ і $B C$, що йдуть в глибину сторони квадрата будуються за допомогою дистанційної точки $D$ згідно з правилами побудови масштабу глибини. На перетині діагоналей квадрата буде розташовуватися точка $O$ центр кола. Через точку $O$ проводяться горизонтальна пряма і пряма $O P$. Ці прямі, будучи осями симетрії квадрата і кола, перетнуть сторони квадрата в точках 1, 2, 3 і 4. Дані точки позначають місця торкання еліпса до сторін квадрата.

На діагоналях квадрата можна побудувати, щонайменш, ще чотири точки еліпса. Так, щоб побудувати точки 5 і 7, викреслюється рівнобедрений прямокутний трикутник $A N 1$ і відкладається відрізок $N^{\prime} 1$, що дорівнює меншій стороні трикутника. Далі проводиться пряма $N^{\prime} P$, що перетинає діагоналі трикутника в шуканих точках 5 і 7. Щоб побудувати ще дві точки еліпса, проводяться горизонтальні прямі через точки 5 і 7. Місця перетину цих прямих з діагоналями квадрата позначають розташування даних точок (вони позначені цифрами 6 і 8). На завершальному етапі побудови точки еліпса від 1 до 8 з'єднуються плавними кривими лініями.

Іноді, для того щоб домогтися більшої точності побудови, виникає необхідність знайти перспективне розташування додаткових точок кола. Для цього в нижній частині зображення можна викреслити фрагмент кола у фронтальній площині з радіусом, рівним половині сторони квадрата $A B C E$. В даному випадку це дуга з центром в точці $O^{\prime}$, що стосується боку квадрата в точці 1 . На дузі відкладається довільно взята точка $L$. з цієї точки проводиться перпендикуляр до сторони квадрата, що перетинає іiі в точці $L_{0}$. Далі на прямій $A B$ відкладається відрізок $L_{0}-1$ ', що дорівнює відрізку $L_{0}-L$. Потім точка $l^{\prime}$ 3'єднується $з$ дистанційною точкою $D$. у місці перетину прямих $L_{0}-P$ i $L^{\prime}-D$ буде розташовуватися точка $L^{\prime \prime}$, яка $€$ однією з точок еліпса. Аналогічним чином можна побудувати ряд інших точок кола в перспективі.

Дуже важно визначити, що подібний спосіб знаходження додаткових точок кола придатний лише при

(C) Журило А. Г., Сівак Є. М. 
побудові великих еліпсів. Побудова невеликих кіл в перспективі таким способом не має сенсу, оскільки в цьому випадку неминучі графічні похибки призводять до значного спотворення форми.

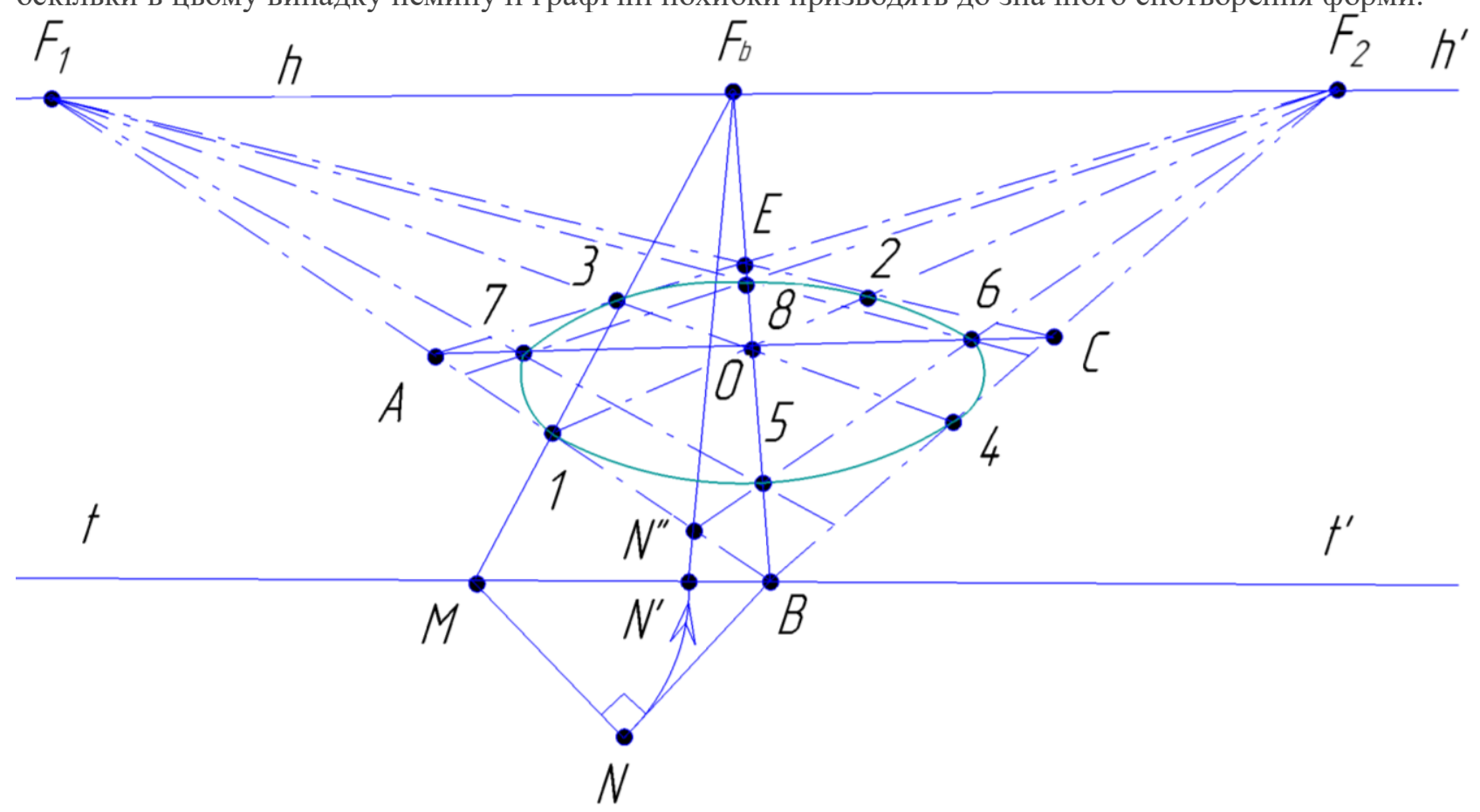

Рис. 3 - Побудова перспективи кола способом описаного квадрата в кутовий перспективі

На Рис. 3 показаний приклад побудови кола, вписаної в квадрат $A B C D$, розташований в кутовий перспективі і стосується підстави картини (квадрат може бути побудований одним з описаних вище способів побудови перспективи). Спочатку проводяться діагоналі квадрата і в місці їх перетину визначається точка $O$ - центр майбутньої окружності, з якої проводяться прямі до точки сходу $\mathrm{F}_{1}$ i $\mathrm{F}_{2}$. Ці прямі перетнуть сторони квадрата в точках 1, 2, 3 і 4. В даних точках окружність належить сторонам квадрата.

Далі будуються точки кола на діагоналях квадрата. Для визначення місця розташування точок 5 і 6 спочатку з точки $F_{\mathrm{b}}$, що є точкою сходу прямої $B E$, проводиться пряма через точку 1 і перетинає основу картинної площині в точці $M$. Потім будується рівнобедрений прямокутний трикутник $M B N \mathrm{i}$ на основі картинної площині відкладається відрізок MN', що дорівнює MN. Далі проводиться пряма $N^{\prime} F_{\mathrm{b}}$ і в місці перетину даної прямої зі стороною $A B$ відкладається точка $N^{\prime \prime} .3$ цієї точки проводиться пряма в точку сходу $F_{2}$, в місці перетину якої з діагоналями квадрата будуть розташовуватися точки 5 i 6. Якщо через дані точки провести прямі в точку сходу $\mathrm{F}_{1}$, то місця перетину цих прямих 3 діагоналями квадрата будуть позначати положення ще двох точок еліпса, позначених цифрами 7 і 8. Утворені точки від 1 до 8 акуратно з'єднуються кривими лініями.

Легко визначити, що отриманий еліпс $є$ практично ідентичним, наведеному у роботі [9]. Причому, при зображенні еліпса у побудові кола в перспективі наявні те ж проблеми точної побудови, використання лекал, чимала кількість допоміжних побудов. Не дуже полегшує побудову еліпса використання комп'ютерної графіки, бо кількість допоміжних побудов залишається необхідною. Тому, при побудові перспективних зображень 3 метою значного полегшення графічних побудов, варто замість еліпсу будувати овал [10].

Висновки та перспективи подальшого дослідження. Визначено, яким чином коло зображується у перспективних зображеннях, доведено, що еліпс, яким зображується коло у перспективі, має теж властивості, що і еліпс при побудові аксонометричних проекцій. Доведено, що при побудові еліпсу, хоч у перспективі, хоч у аксонометрії, основною проблемою залишаються питання точної побудови еліпсу, необхідність використання лекал, потреба виконання чималої кількості допоміжних побудов. Тому, при можливості, пропонується при виконання кресленика перспективних зображень замість побудови еліпсу використовувати овал.

\section{Список бібліографічного опису}

1. Гордон В. О. Курс начертательной геометрии: учебник / В. О. Гордон, М. А. Семенцов - Огиевский. М.: Наука, 1976. $-432 \mathrm{c}$.

(С) Журило А. Г., Сівак Є. М. 
2. Ланюк А. В. Аксонометрические проекции: учебник / А. В. Ланюк. - М. : Гос. изд - во лит - ры по строительству и архитектуре, $1956 .-176 \mathrm{c}$.

3. Порсин Ю. Я. Аксонометрические изображения машиностроительных деталей: учебник / Ю. Я. Порсин. М.- Л. : Машгиз, 1973. - 188 с.

4. Соловьев С. А. Перспектива / С. А. Соловьев.- М.: Просвещение, 1981. - 144c.

5. Соловьев С. Д. та інш. Черчение и перспектива / С. А. Соловьев. - М.: Высшая школа, 1982.

6. Журило А. Г. Теоретичні та практичні основи аксонометрії [Текст] / А. Г. Журило. Навч. посібник. Х.: НТУ «ХПІ». - 2010. - $196 \mathrm{c}$

7. Петерсон В. Е. Перспектива / В. Е. Петерсон. М.:Просвещение, 1970. - 184 с.

8. Ратничин В. М. Перспектива / В. М. Ратничин. Киев, Вища школа, 1982.- 232 с.

9. Журило А. Г. Деякі питання щодо креслення кіл при побудові аксонометричних проекцій / А. Г. Журило, Є. М. Сівак // Комп’ютерно - інтегровані технології: освіта, наука, виробництво. - 2017. - №26. - С. 93-98. Видавництво Луцького національного технічного університету.

10. Журило А. Г. Построение перспективных изображений при отображении картинной плоскости / А. Г. Журило, Е. М. Сівак, И. Ю. Адашевская // Вестник НТУ «ХПИ». № 17, 2014. С. 73-79.

\section{References}

1. Gordon V. O. Kurs nachertatel'noj geometrii: uchebnik / V. O. Gordon, M. A. Semencov - Ogievskij. - M.: Nauka, 1976. $-432 \mathrm{~s}$.

2. Lanyuk A. V. Aksonometricheskie proekcii: uchebnik / A. V. Lanyuk. - M. : Gos. izd - vo lit - ry po stroitel'stvu i arhitekture, 1956. - $176 \mathrm{~s}$.

3. Porsin Yu. Ya. Aksonometricheskie izobrazheniya mashinostroitel'nyh detalej: uchebnik / Yu. Ya. Porsin. - M.- L. : Mashgiz, 1973. - 188 s.

4. Solov'ev S. A. Perspektiva / S. A Solov'ev.- M.: Prosveshchenie, 1981. - 144s.

5. Solov'ev S. A. ta insh. Cherchenie i perspektiva / S. A. Solov'ev. - M.: Vysshaya shkola, 1982.

6. Zhurilo A. G. Teoretichni ta praktichni osnovi aksonometriï [Tekst] / A. G. Zhurilo. Navch. posibnik. H.: NTU «HPI». - 2010. - $196 \mathrm{~s}$.

7. Peterson V. E. Perspektiva / V. E. Peterson. M.:Prosveshchenie, 1970. - 184 s.

8. Ratnichin V. M. Perspektiva / V. M. Ratnichin. Kiev, Vishcha shkola, 1982.- 232 s.

9. Zhurilo A. G. Deyaki pitannya shchodo kreslennya kil pri pobudovi aksonometrichnih proekcij / A. G. Zhurilo, E. M. Sivak // Komp’yuterno - integrovani tekhnologiï: osvita, nauka, virobnictvo. — 2017. - №26. - S. 93-98. Vidavnictvo Luc'kogo nacional'nogo tekhnichnogo universitetu.

10. Zhurilo A. G. Postroenie perspektivnyh izobrazhenij pri otobrazhenii kartinnoj ploskosti / A. G. Zhurilo, E. M. Sivak, I.

Yu. Adashevskaya // Vestnik NTU «HPI». № 17, 2014. S. 73-79.

\section{Рецензенти:}

Заступник начальника кафедри

інженерної та аварійно-рятувальної

техніки Університету цивільного

захисту України, д-р техн. наук, професор Л. М. Куценко

Доцент кафедри Геометричного моделювання та комп’ютерної графіки НТУ «ХПІ», канд. техн. наук 